\title{
ЧАСОВІ КРИТЕРІЇ БЕЗПЕЧНОСТІ ВИКОНАННЯ ГІСТЕРОРЕЗЕКТОСКОПІЧНОӦ МІОМЕКТОМІї ПРИ ОДИНОЧНІЙ СУБМУКОЗНІЙ МІОМІ МАТКИ
}

\author{
๑І. 3. Гладчук, Ю. О. Чеханов, К. В. Латій \\ Одеський національний медичний університет
}

РЕзЮМЕ. Мета - Визначити залежність між тривалістю гістероскопічної міомектомії і показниками дефіциту рідини, використовуваної для іригації, у пацієнток з одиночною субмукозною міомою.

Матеріал і методи. В рамках проспективного дослідження 78 жінкам віком від 20 до 50 років була проведена гістерорезектоскопія за стандартною методикою. Тривалість операції і фактичний дефіцит розчину (експозиція промивної рідини в порожнині матки під час резекції міоми) фіксувалися і аналізувалися в ході дослідження.

Результати. Показники тривалості операції, а також дефіциту розчину розподілилися наступним чином: група

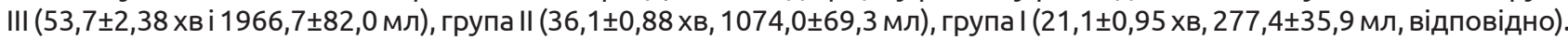

Висновки. Тривалість резекції міоми може служити надійним критерієм для оцінки безпеки проведення операції.

КлючовІ СловА: міомектомія; іригація; субмукозна міома; резекція.

Вступ. Гістерорезектоскопія вже тривалий час застосовується для хірургічного лікування широкого спектра внутрішньоматкової патології. Оскільки переваги цієї малоінвазивної хірургічної методики, порівняно з іншими методами лікування, беззаперечні, то кількість гістероскопічних процедур зростає щорічно $[1,4,6]$. Цілком очікувано, що збільшується і абсолютна кількість ускладнень, притаманних методу. Сукупний показник частоти інтраопераційних, ранніх та пізніх післяопераційних ускладнень гістероскопії коливається в широких межах і становить від 1 до 10 \% [1, 4]. Значна кількість ускладнень припадає на ускладнення гістероскопічної міомектомії як однієї з найчастіших гістероскопічних операцій $[2,3,5,8]$.

Невтішна тенденція до збільшення кількості ускладнень гістероскопічної міомектомії, серед яких трапляються і поодинокі випадки з летальним наслідком, певною мірою пов'язана з недостатньо коректним передопераційним обстеженням та дефектами на етапі інтраопераційного моніторингу [1, 4].

Одним із частих та специфічних ускладнень гістероскопічної міомектомії є інтравазація рідини, яка використовується для розширення та промивання порожнини матки. Показник дефіциту розчину вважається ключовим параметром оцінки безпечності резекції субмукозної міоми матки $[1,4,11,14]$. За умови регламентованого діапазону внутрішньоматкового тиску (70-130 мм рт. ст.), основним фактором, від якого залежить величина інтравазації рідини, залишається тривалість операційного втручання. Цей факт, на нашу думку, дає можливість орієнтуватись на час як базовий критерій безпеки під час операції.

Мета - дослідити кореляцію між показниками дефіциту рідини та часом виконання гістеро- скопічної міомектомії у пацієнток з поодинокою субмукозною міомою матки.

Матеріал і методи дослідження. До даного проспективного дослідження було включено 78 жінок із субмукозною міомою матки, які скаржилися на гіперменорею (94,9\%), болі внизу живота (19,2 \%), безпліддя (11,5 \%). Віковий діапазон коливався в межах від 20 до 50 років. Усім хворим на догоспітальному етапі проводили трансвагінальне УзД. Для уточнення діагнозу проводили соногістерографію та МРТ. Трансвагінальна УЗД та соногістерографія проводились одним спеціалістом у всіх випадках.

Критеріями формування групи хворих були субмукозна міома матки 0, I, II типів; одиночна субмукозна міома матки; діаметр вузла міоми матки від 0,5 до 5 см.

Визначалась також мінімальна товщина міометрія між вузлом та поверхнею матки. До гістерорезектоскопії були допущені лише ті пацієнтки, у яких товщина стінки матки над вузлом була 3 мм та більше, що, на нашу думку, є безпечним для виконання резекції.

Жінки з двома або більше міомними вузлами не увійшли до дослідження.

На передній та задній стінках матки вузли розташовувались у 40 (51,3 \%) хворих, в ділянці бокових стінок - у 23 (29,5 \%), у 15 (19,2 \%) - в ділянці дна матки та маткових кутів.

Відповідно до класифікації ESGE серед 78 обстежених пацієнток у 21 (26,9 \%) субмукозна міома відповідала типу 0, у 30 (38,5 \%) - типу I, у 27 (34,6\%) - типу II.

У всіх пацієнток проводили одно- або двоетапну гістероскопічну міомектомію, під час якої здійснювали контроль тривалості операції, а також контроль використання промивної рідини. 
Огляди літератури, оригінальні дослідження, погляд на проблему

Для забезпечення чистоти дослідження фіксували лише реальну експозицію промивання порожнини матки. Тому під тривалістю операції ми розуміємо час, який витрачався безпосередньо на резекцію пухлини, коли порожнина матки була розширена рідиною, без врахування часу, затраченого на механічну евакуацію фрагментів міоми.
Пацієнтки були поділені на три групи залежно від тривалості операції: до групи I увійшли жінки, тривалість операції у яких не превищувала 30 хв, до групи II - від 30 до 45 хв, і до групи III більше 45 хв.

Групи були однорідними за віком, клінічними параметрами, а також топографією субмукозних вузлів (табл. 1, 2).

Таблиця 1. Загальна характеристика хворих з субмукозною міомою матки ( $\mathrm{n=78)}$

\begin{tabular}{|l|c|c|c|}
\hline \multicolumn{1}{|c|}{ Параметр } & \multicolumn{2}{c|}{ Група } \\
\cline { 2 - 4 } & I (<30 хв) & II (30-45 хв) & III (>45 хв) \\
\hline Кількість пацієнтів & 39 & 27 & $40,2 \pm 1,03$ \\
\hline Середній вік & $37,4 \pm 1,32$ & $38,2 \pm 1,3$ & $26,4 \pm 1,9$ \\
\hline IМТ & $23,9 \pm 2,6$ & $25,5 \pm 1,8$ & $43,6 \pm 0,65$ \\
\hline Середній діаметр міоми & $14,9 \pm 1,13$ & $33,6 \pm 0,77$ & $6(50,0 \%)$ \\
\hline Топографія міоми: & & & $4(33,3 \%)$ \\
\hline передня та задня стінки & $20(51,3 \%)$ & $14(51,9 \%)$ & $2(16,7 \%)$ \\
\hline бокові стінки & $11(28,2 \%)$ & $8(29,6 \%)$ & $5(18,5 \%)$ \\
\hline дно та кути матки & $8(20,5 \%)$ & & \\
\hline
\end{tabular}

Таблиця 2. Характеристика субмукозних міом за класифікацією ESGE (n=78)

\begin{tabular}{|c|c|c|c|}
\hline \multirow{2}{*}{$\begin{array}{c}\text { Тип міоми за класифікаці- } \\
\text { єю ESGE }\end{array}$} & \begin{tabular}{c} 
Група \\
І (<30 хв), \\
\cline { 2 - 4 }
\end{tabular} & $\begin{array}{c}\text { II (30-44хв), } \\
\text { a6с. к-ть }(\%)\end{array}$ & $\begin{array}{c}\text { III }(\geq 45 \text { xв), } \\
\text { a6с. к-ть (\%) }\end{array}$ \\
\hline Тип 0 & $15(71,4)$ & $6(18,6)$ & 0 \\
\hline Тип I & $14(46,7)$ & $12(40,0)$ & $4(13,3)$ \\
\hline Тип II & $10(37,1)$ & $9(33,3)$ & $8(29,6)$ \\
\hline
\end{tabular}

Оцінку радикальності гістероскопічної міомектомії здійснювали інтраопераційно за допомогою прямого візуального контролю, а також за даними УЗД, проведеного безпосередньо після операції.

Внутрішньоматковий тиск під час операції знаходився в межах 70-110 мм рт. ст. і підтримувався автоматично завдяки використанню гістеромата.

Жодної перфорації зафіксовано не було.

Перед- та післяопераційна гормональна терапія не використовувалась в жодному з випадків.

Операційна методика. Операція проводилась із застосування внутрішньовенної анестезії пропофолом у загальноприйнятих дозах.

Втручання проводили на обладнанні фірми Karl Srorz. Використовували високочастотний гістерорезектоскоп діаметром 8,6 мм з безперервним потоком рідини. Візуальний контроль здійснювали за допомогою 4-міліметрової оптики Karl Srorz з кутом огляду $30^{\circ}$ для постійного контролю за ріжучим елементом. Основним середовищем для розширення та промивання порожнини матки був 5 \% розчин глюкози. Автоматичний мікропроцесорний контроль всмоктування та проми- вання, а також контроль дефіциту використаної рідини в реальному часі здійснювався завдяки Endomat@ Hamou - електронному відсмоктувачуіригатору.

Операційна техніка була типовою $[4,6,13]$. В асептичних умовах після обробки операційного поля антисептиком шийка матки фіксувалась кульовими щипцями. Проводили дилатацію цервікального каналу до номеру 9 розширювачів Гегара. Під візуальним контролем вводили гістерорезектоскоп. Здійснювали промивання порожнини матки до оптимальної візуалізації. Проводили ревізію порожнини матки, звертаючи увагу на вічка маткових труб, форму порожнини матки, стан слизової оболонки матки. Визначали топографію міоми, уточнювали ії тип та розмір. Хірургічний етап операції проводили із застосуванням петлевого електрода і техніки резекції міоми «рухом на себе». Евакуацію шматків міоми здійснювали кюреткою або петлею електрода. У частини пацієнток $(37,6$ \%) з типами міоми I і II використовували внутрішньовенне введення утеротонічного розчину окситоцину.

Результати й обговорення. Гістерорезектоскопія - операція першої лінії допомоги пацієнт- 
Огляди літератури, оригінальні дослідження, погляд на проблему

кам фертильного віку із субмукозною міомою матки, які бажають зберегти матку. Контроль за витратою розчину, раннє розпізнавання симптомів перевантаження та вибір адекватної рідини для розширення матки є базовими заходами для запобігання небажаним наслідкам операції $[4,10$, $13,15]$.

Задля уникнення ускладнень, пов'язаних з надмірною абсорбцією рідини, слід дотримуватись ключових правил, основним з яких $є$ мінімізація надходження дистенційного розчину до системи гемоциркуляції.

Забезпечити адекватний тиск для виконання гістероскопічної міомектомії можливо декількома способами: гравітаційним, механічною помпою, або ж за допомогою контрольованих електронікою систем - ендоматів. Проте жоден з цих методів не може запобігти надмірному поглинанню рідини і виникненню ускладнень, що іноді можуть загрожувати життю пацієнтки.

Загальноприйнято вважати пороговим дефіцит 1000 мл розчину, тоді як показник 1500 млє критичним і потребує негайного прийняття рішення щодо перспективи завершення резекції субмукозної міоми $[4,9,11,12,14]$. Максимально допустимою, за рекомендацією AAGL від 2012 року, є інтравазація 2500 мл промивного розчину. Але цей показник не $\epsilon$ абсолютним [4]. Потрібно враховувати індивідуальні характеристики хворої, такі як тип статури, наявність супутньої екстрагентітальної патології та ін. [3, 5, 6, 7].

Раннє розпізнавання надмірної абсорбції повинно базуватися на постійному моніторингу кількості введеної та виведеної промивної рідини, що не завжди легко здійснити. Дані щодо показників дефіциту рідини повинні бути в полі зору хірурга під час операції. І, звичайно, в таких умовах віддається перевага електронним системам контролю, оскільки «ручний» підрахунок створює додаткові труднощі, особливо при тривалих операціях [4]. Крім того, часто технічно неможливо мати достатню кількість вільного персоналу, щоб доручити функцію такого підрахунку окремій людині, не зайнятій в операційній, особливо в разі застосування механічних способів створення та підтримання внутрішньоматкового тиску.

Відомо, що збільшення інтенсивності абсорбції відбувається, коли цифри перевищують системний артеріальний тиск. Це діапазон - 90-132 мм вод. ст. $[4,9,11]$. Про це треба пам'ятати, розміщуючи контейнер з рідиною на певній висоті або під час встановлення параметрів на ендоматі. Власне кажучи, внутрішньоматковий тиск повинен бути максимально низький для забезпечення адекватної візуалізації, кращий варіант - його індивідуальна регуляція залежно від клінічної ситуації.

Вибір рідини для розширення порожнини матки також $є$ важливим завданням на етапі передопераційного планування. Корисним в цьому випадку може бути застосування "дуету» біполярний гістероскоп і фізіологічний розчин $[8,9$, 12]. Використання речовин з нормальною осмолярністю має менший вплив на зміну концентрації натрію в сироватці крові [8]. Але і це не знімає проблеми надмірної абсорбції і потребує прискіпливого контролю, оскільки перевантаження рідиною може викликати набряк легень і навіть призвести до смерті.

Отримані в ході дослідження дані демонструють залежність між показниками дефіциту рідини та тривалістю операційного втручання в усіх трьох групах (табл. 3).

Таблиця 3. Характеристика параметрів операційних втручань у трьох групах хворих

\begin{tabular}{|c|c|c|c|}
\hline \multirow{2}{*}{ Показник } & \multicolumn{3}{|c|}{ Групи } \\
\hline & I (до 29 хв) & II $(30-44$ xв) & III ( $\geq 45 \times$ Xв) \\
\hline 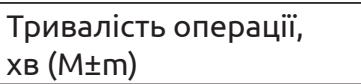 & $21,1 \pm 0,95$ & $36,1 \pm 0,88$ & $53,7 \pm 2,38$ \\
\hline $\begin{array}{l}\text { Тривалість операції } \\
\text { (діапазон, хв) }\end{array}$ & $10-29$ & $30-44$ & $45-68$ \\
\hline 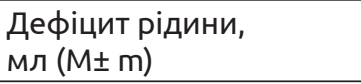 & $277,4 \pm 35,9$ & $1074,0 \pm 69,3$ & $1966,7 \pm 82,0$ \\
\hline $\begin{array}{l}\text { Дефіцит рідини } \\
\text { (діапазон, мл) }\end{array}$ & $50-700$ & $600-1700$ & $1650-2550$ \\
\hline $\begin{array}{l}\text { Кількість завершених } \\
\text { одноетапних операцій, } \\
\text { абс. к-ть (\%) }\end{array}$ & $39(100)$ & $27(100)$ & $9(75,0)$ \\
\hline $\begin{array}{l}\text { Ускладнення, } \\
\text { абс. к-ть (\%) }\end{array}$ & 0 & 0 & $3(25,0)$ \\
\hline
\end{tabular}

В групі I середній час проведення гістерорезектоскопії становив $(21,1 \pm 0,95)$ хв, а середній рівень дефіциту рідини - $(277,4 \pm 35,9)$ мл; в групі II -
$(36,1 \pm 0,88)$ хв та $(1074,0 \pm 69,3)$ мл; в групі III $(53,7 \pm 2,38)$ хв та $(1966,7 \pm 82,0)$ мл відповідно (рис. 1). 


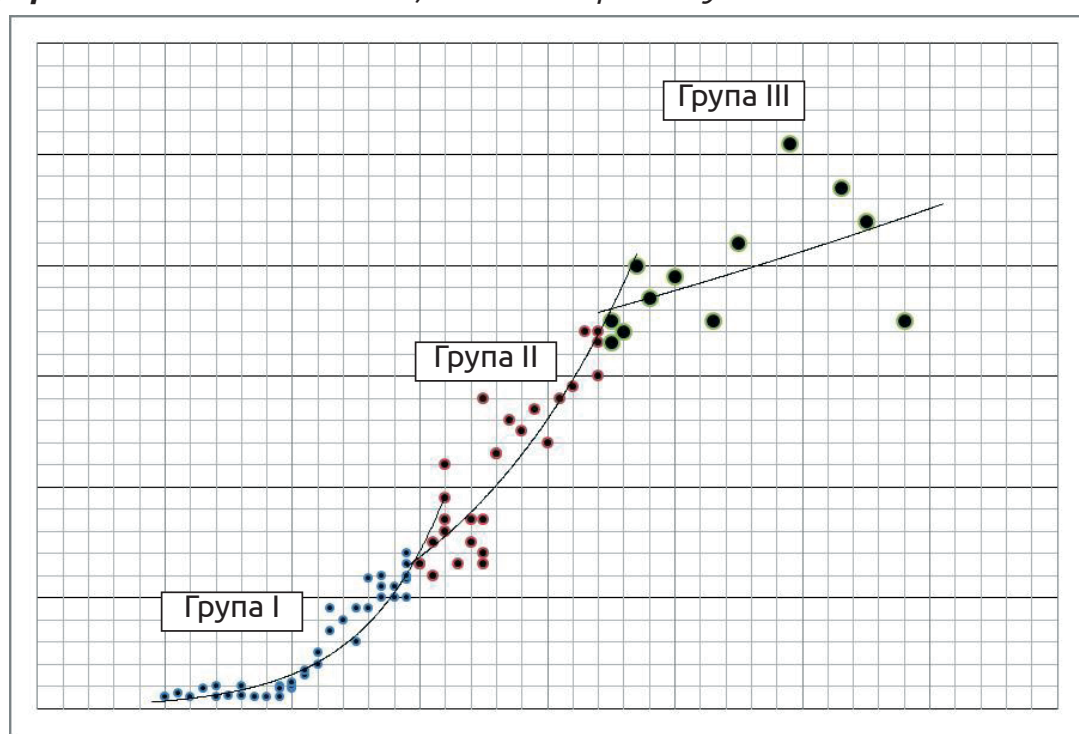

Рис. 1. Взаємозв'язок між тривалістю операції (хв) та дефіцитом рідини (мл) у трьох досліджуваних групах хворих.

В групі III спостерігали три епізоди перевантаження рідиною, що супроводжувалися інтраопераційно брадикардією, гіпертензією та тривалим періодом відновлення в післяопераційному періоді. Гістерорезектоскопія була зупинена на етапі виникнення підозри на ускладнення. Пацієнтки переведені для інтенсивного спостереження до відділення реанімації та інтенсивної терапії. Стан хворих покращився протягом доби на тлі відповідної терапії. Пацієнтки були виписані на наступний день в задовільному стані. В усіх трьох випадках протягом двох місяців була успішно проведена гістерорезектоскопія другим етапом з повним видаленням субмукозної міоми.

Кровотеча під час операції не потребувала зупинки операції в жодному з випадків і максимально становила 300 мл.

Орієнтуючись на отримані дані варто звернути увагу, що всі без винятку операції у пацієнток I групи проведені з показниками дефіциту рідини менше 700 мл. У межах нашого дослідження такі операції з точки зору ризику надмірної інтравазації можна вважати близькими до абсолютно безпечних.

Показники дефіциту рідини в групі II були більш різноманітні. В 13 (56,5 \%) випадках було втрачено до 1000 мл розчину. Серед 27 операцій у 23 (85,2 \%) спостерігався дефіцит до 1500 мл, i лише у 4 (14,8\%) показники перевищували критичний рівень у 1,5 л. Враховуючи той факт, що в переважній більшості випадків (85,2 \%) резектоскопія у таких хворих не супроводжується втратою рідини понад 1500 мл, операції тривалістю від 30 до 45 хв мають, зазвичай, сприятливий перебіг. У 4 (14,8 \%) випадках спостерігалося поглинання надмірної кількості рідини і, як наслідок, виникала загроза здоров'ю пацієнтки. Отже, в проміжку тривалості операції від 30 до 45 хв (15 хв) хірург-гінеколог повинен чітко усвідомлювати можливість завершення процедури в цілому.

Окремо зазначимо, що 11 резекцій міоми в групі II пройшли з показниками дефіциту в діапазоні 1000-1500 мл. Це вказує на те, що за тривалості операції понад 30 хв хірург має час зорієнтуватись і прийняти рішення щодо продовження чи зупинки втручання, перебуваючи у відносно безпечному інтервалі дефіциту дистенційного розчину в межах 1000-1500 мл. В таких випадках ключовим є досвід оператора.

В той самий час, всі гістерорезектоскопії в групі III супроводжувались втратою більше ніж 1500 мл рідини. Зрозуміло, що будь-яка операція тривалістю більше 45 хв є потенційно небезпечною для життя хворої та потребує негайної зупинки з плануванням наступного етапу резектоскопії через певний проміжок часу, що і підтверджує високий рівень ускладнень в цій групі - 25 \%. Додатково зазначимо, що діаметри всіх вузлів у пацієнток із групи III були більше 40 мм. Подібні гістерорезектоскопії можуть проводитись тільки висококваліфікованим хірургом за участі досвідченої бригади анестезіологів-реаніматологів, особливо у випадках I та II типів субмукозних міом.

Висновки. Існує прямий зв'язок між тривалістю операції та дефіцитом рідини при гістероскопічній резекції субмукозної міоми матки. 3 огляду на це, тривалість проведення гістероскопічної операції може використовуватись як надійний критерій безпечності гістерорезектоскопічної міомектомії щодо ризику виникнення надмірної інтравазації. 


\section{Огляди літератури, оригінальні дослідження, погляд на проблему \\ ЛІТЕРАТУРА}

1. A multicenter survey of complications associated with 21, 676 operative hysteroscopies / B. Aydeniz, I. V. Gruber, B. Schauf [et al.] // Eur. J. Obstet. Gynecol. Reprod. Biol. - 2002. - Vol. 104. - P. 160-164.

2. Munro M. G. Complications of hysteroscopic and uterine resectoscopic surgery / M. G. Munro // Obstet. Gynecol. Clin. North Am. - 2010. - No. 37. - P. 399-425.

3. Valle R. F. Hysteroscopic myomectomy hysteroscopy. Visual perspectives of uterine / M. S. Baggish, R. F. Valle, H. Guedj (eds)., Anatomy, Physiology and Pathology Diagnostic and Operative Hysteroscopy. - 3rd edn. - Philadelphia : Lippincott Williams \& Wilkins, a Wolters Kluwer business, 2007. - P. 385-404.

4. AAGL Practice Report: Practice Guidelines for the Diagnosis and Management of Submucous Leiomyomas // Journal of Minimally Invasive. Gynecology. - 2012. - No. 19. P. 152-171.

5. An analysis of hysteroscopy experience over a sevenyear period / E. Ozturk, M. G. Ugur, O. Balat [et al.] // Clin. Exp. Obstet. Gynecol. - 2010. - No. 37. - P. 150-151.

6. Stamatellos I. Hysteroscopic myomectomy / I. Stamatellos, J. Bontis // Eur. Clinics. Obstet. Gynecol. - 2007. No. 3. - P. 17-23.

7. The management of uterine leiomyomas., Special Contributors / G. A. Vilos, C. Allaire, P. Y. Laberge, N. Leyland // Journal of Obstetrics and Gynaecology. - 2015. Vol. 37 (2). - P. 157-181.

8. Agdi M. Minimally invasive approach for myomectomy / M. Agdi, T. Tulandi // Seminars in Reproductive Medicine. - 2010. - Vol. 28 (3). - P. 228-234.

\section{REFERENCES}

1. Aydeniz, B., Gruber, I.V., Schauf, B., Kurek, R., Meyer, A. \& Wallwiener, D. (2002). A multicenter survey of complications associated with 21,676 operative hysteroscopies. Eur. J. Obstet. Gynecol. Reprod. Biol., 104, 160-164.

2. Munro, M.G. (2010). Complications of hysteroscopic and uterine resectoscopic surgery. Obstet. Gynecol. Clin. North Am., 37, 399-425.

3. Valle R. F. Hysteroscopic myomectomy. In: M. S. Baggish, R. F. Valle, H. Guedj (Eds). (2007). Hysteroscopy. Visual perspectives of uterine anatomy, physiology and pathology diagnostic and operative hysteroscopy, 3rd edn. Philadelphia: Lippincott Williams \& Wilkins, a Wolters Kluwer business, 385-404.

4. (2012). AAGL Practice Report: Practice Guidelines for the Diagnosis and Management of Submucous Leiomyomas. Journal of Minimally Invasive. Gynecology, 19, 152-171.

5. Ozturk, E., Ugur, M.G., Balat, O., Kutlar, I., Dikensoy, E. \& Cebesoy, B. (2010). An analysis of hysteroscopy experience over a seven-year period. Clin. Exp. Obstet. Gynecol., 37, 150-151.

6. Stamatellos, I. \& Bontis, J. (2007). Hysteroscopic myomectomy. Eur. Clinics Obstet. Gynecol., 3, 17-23.

7. Vilos, G.A., Allaire, C., Laberge, P.Y. \& Leyland, N. (2015). The management of uterine leiomyomas. Special Contributors, Vilos, A.G., Murji, A., Chen, I. Journal of Obstetrics and Gynaecology Canada: JOGC, 37 (2), 157-181.
9. Uterine synechiae after bipolar hysteroscopic resection of submucosal myomas in patients with infertility / C. Touboul, H. Fernandez, X. Deffieux [et al.] // Fertil. Steril. - 2009. - No. 92. - P. 1690-1693.

10. Biological effects of distension media in bipolar versus monopolar resectoscopic myomectomy: a randomized trial / A. M. Darwish, Z. Z. Hassan, A. M. Attia [et al.] // J. Obstet. Gynaecol. Res. - 2010. - No. 36. - P. 810-817.

11. Indman P. D. Hysteroscopic treatment of submucous fibroids / P. D. Indman // Clin. Obstet. Gynecol. - 2006. No. 49. - P. 811-820.

12. Sethi N. Operative hysteroscopy intravascular absorption syndrome: A bolt from the blue / N. Sethi, R. Chaturvedi, K. Kumar // Indian J Anaesth. - 2012. - Vol. 56 (2). P. 179-182. DOI: 10.4103/0019-5049.96342.

13. Capmas P. Surgical techniques and outcome in the management of submucous fibroids / P. Capmas, J. M. Levaillant, H. Fernandez // Curr. Opin. Obstet. Gynecol. - 2013. Vol. 25(4).-P.332-338.DOI:10.1097/GCO.0b013e3283630e10.

14. Fonseca Mde F. Predictors of fluid intravasation during operative hysteroscopy: a preplanned prospective observational study with 200 cases / F. Fonseca Mde, C. M. Andrade Junior, A. Nogueira Ede // Rev. Bras. Ginecol. Obstet. - 2015. - Vol. 37 (1). - P. 24-29. DOI: 10.1590/ S0100-720320140005139.

15. Predicting success of single step hysteroscopic myomectomy: A single centre large cohort study of single myomas / I. Mazzon, A. Favilli, M. Grasso [et al.] // Int. J. Surg. - 2015. - № 22. - P. 10-14. DOI: 10.1016/j. ijsu.2015.07.714. Epub 2015 Aug 12.

8. Agdi, M. \& Tulandi, T. (2010). Minimally invasive approach for myomectomy. Seminars in Reproductive Medicine, 28 (3), 228-234.

9. Touboul, C., Fernandez, H., Deffieux, X., Berry, R., Frydman, R. \& Gervaise, A. (2009). Uterine synechiae after bipolar hysteroscopic resection of submucosal myomas in patients with infertility. Fertil. Steril., 92, 1690-1693 (II-3).

10. Darwish, A.M., Hassan, Z.Z., Attia, A.M., Abdelraheem, S.S. \& Ahmed, Y.M. (2010). Biological effects of distension media in bipolar versus monopolar resectoscopic myomectomy: a randomized trial. J. Obstet. Gynaecol. Res., 36, 810-817 (I).

11. Indman, P.D. (2006). Hysteroscopic treatment of submucous fibroids. Clin. Obstet. Gynecol., 49, 811-820.

12. Sethi, N., Chaturvedi, R. \& Kumar, K. (2012). Operative hysteroscopy intravascular absorption syndrome: A bolt from the blue. Indian J. Anaesth., 56 (2), 179-182. doi: 10.4103/0019-5049.96342.

13. Capmas, P., Levaillant, J.M. \& Fernandez, H. (2013). Surgical techniques and outcome in the management of submucous fibroids. Curr. Opin. Obstet. Gynecol., 25 (4), 332-338. doi: 10.1097/GCO.0b013e3283630e10.

14. Fonseca Mde, F., Andrade Junior, C.M., Nogueira Ede, A, Sessa, F.V. \& Crispi, C.P. (2015). Predictors of fluid intravasation during operative hysteroscopy: a preplanned prospective observational study with 200 cases. Rev. Bras. Ginecol. Obstet., 37(1), 24-29. doi: 10.1590/S0100-720320140005139. 
Огляди літератури, оригінальні дослідження, погляд на проблему

15. Mazzon, I., Favilli, A., Grasso, M., Horvath, S, Bini,

large cohort study of single myomas. Int. J. Surg., 2210V., Di Renzo, G.C. \& Gerli, S. (2015). Predicting success of single step hysteroscopic myomectomy: A single centre

2214. doi: 10.1016/j.ijsu.2015.07.714. Epub 2015 Aug 12.

\title{
ВРЕМЕННЫЕ КРИТЕРИИ БЕЗОПАСНОСТИ ВЫПОЛНЕНИЯ ГИСТЕРОРЕЗЕКТОСКОПИЧЕСКОЙ МИОМЭКТОМИИ ПРИ ОДИНОЧНОЙ СУБМУКОЗНОЙ МИОМЕ МАТКИ
}

\author{
○И. З. Гладчук, Ю. О. Чеханов, К. В. Латий \\ Одесский национальный медицинский университет
}

РЕЗЮМЕ. Цель - определить зависимость между продолжительностью гистероскопической миомэктомии и показателями дефицита жидкости, используемой для ирригации, у пациенток с единичной субмукозной миомой.

Материал и методы. В рамках проспективного исследования, 78 женщинам возрастом от 20 до 50 лет была проведена гистерорезектоскопия по стандартной методике. Продолжительность операции и фактический дефицит раствора (експозиция промывной жидкости в полости матки во время резекции миомы) фиксировались и анализировались в ходе исследования.

Результаты. Показатели длительности операции, а также, дефицита раствора распределились следующим

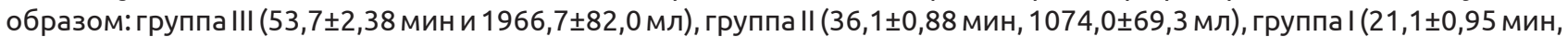
$277,4 \pm 35,9$ мл, соответственно).

Выводы. Длительность резекции миомы может служить надежным критерием для оценки безопасности проведения операции.

КЛЮЧЕВЫЕ СЛОВА: миомэктомия; ирригация; субмукозная миома; резекция.

\section{TIME CRITERIA FOR THE SAFETY OF HYSTEROESTHETIC MYOMECTOMY AT SINGLE SUBMUCOSOMAL UTERUS}

\author{
@I. Z. Hladchuk, Yu. O. Chekhanov, K. V. Latii \\ Odesa National Medical University
}

SUMMARY. The aim of the study - to determine the correlation between duration of hysteroscopic myomectomy and the rates of irrigation fluid deficit in patients with single submucous myoma.

METHODS. Prospective observational study. All cases ( $n=78$ women; 20 to 50 years old) were treated using standard operating technique. The duration of the procedure rates and the actual fluid deficit (the exposition of the distension media in uterine cavity during nodule resection) were controlled and analyzed.

RESULTS. Operation duration and mean fluid deficit were presented as follows: group III (53.7 $\pm 2.38 \mathrm{~min}$ and $1966.7 \pm 82.0 \mathrm{ml})$, group II (36.1 $\pm 0.88 \mathrm{~min}, 1074.0 \pm 69.3 \mathrm{ml})$, group I ( $21.1 \pm 0.95 \mathrm{~min}, 277.4 \pm 35.9 \mathrm{ml}$, respectively).

CONCLUSIONS. Duration of hysteroscopic myomectomy can be used as reliable criteria to evaluate safety of the operative procedure.

KEY WORDS: myomectomy; irrigation; submucous myoma; resection. 